\title{
Open Course Development at the OERu
}

\author{
Wayne Mackintosh \\ OER Universitas (OERu) \& OER Foundation, wayne@oerfoundation.org
}

\section{Editors' Commentary}

As the Massive Open Online Courses (MOOCs) produced by Ivy League institutions and driven by venture capitalists continue to pivot away from promises of serving the underserved, an international network of 30+ like-minded institutions known as the OERu have been quietly taking steps towards offering a free first year program of study for learners anywhere in the world. In this chapter, author Wayne Mackintosh describes the principles and processes of open course design and development that serve as the foundation of the network and its goal of providing free, open, flexible, student-centered, credit bearing, online education.

'I was excited to be offered something different and to be part of a pilot project,' reports Michelle Aragon, who in 2014 made history by becoming the first student to receive academic credit for completing a course through the OERu. Using free, open educational resources (OERs), and without leaving her home in Penticton in British Columbia, Canada, Michelle wrote a paper on child poverty in the Philippines and created a travel brochure on Bali's eco-tourism industry. Furthermore, as an OERu course, the only fees were to have her assignments and exams graded. 'I do feel a course like this requires a higher level of technological and research skills', she adds. 'The expectation is for the student to access open resources online. That can be challenging but it's part of what makes taking this course a great experience.'

How to cite this book chapter:

Mackintosh, W. 2017. Open Course Development at the OERu. In: Jhangiani, R S and Biswas-Diener, R. (eds.) Open: The Philosophy and Practices that are Revolutionizing Education and Science. Pp. 101-114. London: Ubiquity Press. DOI: https://doi.org/10.5334/bbc.h. License: CC-BY 4.0 
Aragon, then a student in Thompson Rivers University-Open Learning's General Studies Diploma program, enrolled in AST1000: Regional Relations in Asia and the Pacific, a course created by OERu partner, the University of Southern Queensland (USQ) in Australia. USQ implemented a course design based on a pedagogy of discovery whereby learners identify OERs in pursuit of their own interests in achieving the learning outcomes for the course. 'This was an exciting opportunity for me as facilitator,' says Dr Marcus Harmes from USQ, 'and I believe for Michelle as learner to take an approach to study that allowed her to follow personal interests and areas of passion - the outcomes were excellent.'

\section{Introduction}

Open course design and development at the OER universitas (OERu) flows from the culture of openness embedded into the OER Foundation (OERF). Consequently, any discussion about open course development must be situated and understood within the organisational context of the OER Foundation.

This chapter begins with a summary of the OER Foundation including its history, values, and its distinctly open operations. This background discussion will be followed by a succinct introduction of the OERu international innovation partnership. This discussion will provide the framework for reflecting on the open design and development practices at the OERu.

\section{Organisational context of the OER Foundation}

The Open Education Resource Foundation (OERF) is an independent notfor-profit organisation that provides leadership, international networking and support for educational institutions to achieve their strategic objectives using open education approaches.

\section{Words are important}

First, a note about nomenclature. We are not the 'Open Educational Resources' Foundation. For us, 'open education' is an umbrella concept encompassing multiple dimensions of openness including Open Educational Resources (OER), Open Educational Practices (OEP), Open licensing, open policy, free and open source software (FOSS), and open philanthropy. Resource (singular) is used as a noun to infer that openness is the primary means and enabler to achieve more sustainable education futures for all. Openness is the DNA of the OERF - we do not do closed as a matter of policy.

\section{Conceived from failed innovation and organisational closedness}

A strategy innovator by nature, I established the OER Foundation out of frustration with the slow rate of progress combined with the lessons learned from 
failed innovation attempts to transform educational institutions towards the mainstream adoption of open education approaches to leverage the affordances of a digital age in widening access to educational opportunity. The most important lesson learned was that the inertia of existing operations and business practices at many organisations is frequently too strong to achieve the critical mass required for substantive transformation towards open practices (see also Chapter 13 by Farhad Dastur).

To illustrate this point, I am a committed advocate and user of free software for education. Previously I was recruited to join an institution working in the field of open learning with full disclosure of my preferences for using FOSS. When it came to acquiring a new laptop on joining the institution, I suggested that I would use my existing machine which was customised with my personal flavour of the GNU-Linux operating system. I was informed that this would not be possible because the enterprise was required to 'maintain the image' which I subsequently found out was the Microsoft desktop image. It is a contradiction in terms to espouse open learning but to demand that individuals must sacrifice their freedoms in technology choice by requiring the use of proprietary technology.

I do not use non-free software as a matter of personal choice and my reticence to use non-free software was escalated to executive level. I received official notification that as an exception, I would be permitted to install a GNULinux operating system on an external hard drive with the enterprise issue of the Microsoft operating system installed on the laptop. I responded in writing that I would accept this requirement only if every other staff member in the organisation was required to have GNU-LINUX installed on their notebooks and provided with permission to boot Microsoft from an external hard drive. Fortunately, the organisation had the foresight to see the absurdity of discriminating against open systems and allowed me to run an open source operating system on the corporate notebook on condition that I did not generate support dependencies using a different system which was a fair and reasonable solution.

\section{Cooperative independence as strategy for open transformation}

Over two-decades of focused effort in attempting open transformation from within organisations, in the absence of satisfactory progress, it became clear that perhaps substantive transformation for openness could be better achieved through an independent organisation cooperating with existing educational institutions in the formal sector. I don't buy into the rhetoric of 'disruptive innovation' that universities are doomed to extinction. Universities are important organs of society. They are one of only a handful of organisations that have survived the industrial revolution and, if history repeats itself, they will survive deep into the knowledge revolution.

Early in 2009, we established the OERF as an independent charity. When searching for a suitable home for the Foundation, the best choice was to locate the new institution at Otago Polytechnic in New Zealand because they were the 
first tertiary institution in the world to adopt a Creative Commons Attribution intellectual property policy and the Council of the Polytechnic had the courage to register the OERF as an independent charitable entity.

The inkling that cooperative independence would be more effective in nurturing the development of sustainable ecosystems working towards the mainstream adoption of open education in the formal sector is paying dividends in the case of the OERF. As of 2016 the Foundation has no accumulated debt and its membership continues to grow at a steady pace. Currently the network comprises over thirty institutions from Africa, Europe, the Middle East, North America, Oceania, and South-East Asia.

\section{Modelling the OERF structure on successful open source software foundation structures}

The OERF is modelled on the organisational structures derived from successful open source software foundations like the Apache Software Foundation ${ }^{2}$ and the Mozilla Foundation. ${ }^{3}$

The OERF, governed by an international Board of Directors, provides the legal framework for coordinating a number of flagship initiatives which operate as independent community projects. The OER Foundation is a social enterprise whereby money earned through our projects are invested back into the charitable education activities of the Foundation.

Meritocracy is a guiding principle of the OERF. Leadership roles in our community projects are 'earned' through sustained performance. Individuals who have gained respect from their community peers through engagement have a greater influence on decision-making. Transparent planning promotes trust in our open decision-making practices.

\section{Flagship initiatives}

The OERF administers a number of flagship initiatives in open education: OERu, WikiEducator, and hosts Creative Commons Aotearoa New Zealand.

The OERu is an international innovation partnership of universities, colleges, and polytechnics who are working together to provide more affordable and accessible higher education. WikiEducator is an international community of $60,000+$ educators collaborating on the development of OER. CCANZ is the New Zealand national affiliate of Creative Commons and operates as a self-funded project.

\section{Openness as principle not an optional feature}

The OERF subscribes to the principles of open philanthropy and open governance for its operations and projects. Open philanthropy promotes radical transparency, 
sharing, and collaboration to effect social change in education. The OERF supports and encourages autonomy and open governance of its flagship projects. This enables the OERF to provide a clear distinction between legal and financial governance and the community-based operations of our flagship initiatives while providing the agility for individual projects to mature utilizing shared infrastructure. This networked model provides a low risk, low cost, but high impact innovation platform for institutions wanting to engage with open education.

\section{Open planning}

All planning activities of the Foundation's flagship initiatives are conducted openly and transparently. For example, the planning activities of the OERu project are hosted on WikiEducator with the freedom for any member of the public to help shape our futures. All partner meetings since inception of the OERu are streamed live on the internet encouraging wide international participation. The OERu project uses an open consensus model for decision-making and members from the open community also participate through the wiki and open email lists.

\section{Open policy}

As a general practice informed by the core values of the institution, the OERF staff do not participate in projects in their official capacity where the outputs are not licensed under a free cultural works approved open license. The free cultural works definition is derived from the essential freedoms associated with the free software movement. ${ }^{4}$ So for example, restricting derivative works or commercial activity are a deemed to be material restrictions of freedom. Moreover, free cultural works approved artefacts must be stored in editable and open file formats. With reference to the suite of Creative Commons licenses discussed in Chapter 3, the Attribution and Attribution ShareAlike licenses and works dedicated to the public domain meet the requirements of free cultural works. In addition, we encourage that funding proposals are developed transparently and endorsements or participation from the OERF in philanthropic partnerships prefers that these documents are openly licensed. While some competing for contestable funding in open education are uncomfortable sharing proposals under open licenses, we at the OERF believe that if anyone 'steals' our ideas and can do what we propose quicker, cheaper or of better quality then they deserve the funding. When outputs are released openly, as in the case of OER, we all benefit and the ecosystem grows. Requiring open licensing for joint funding proposals developed openly is also a great way to discern intent. We are sometimes approached by organisations to endorse or participate in peripheral capacities in joint proposals as mechanism to use the association with the OERF as an attempt to boost the likelihood of funding success. 
Organisations who are unwilling to work openly care less about open than we do and are therefore not likely to be productive partners.

\section{Open technology}

As an open education project, the OERF uses FOSS exclusively for our enterprise infrastructure and we promote the use of open file formats. We use the same software as the popular Wikipedia website with a proven track record for security, reliability and scalability. Apart from the significant cost efficiencies gained from using FOSS, our choice is a values-based decision. In this way we can ensure that no educator in the world is restricted from participating in OER because they have to purchase software licenses or sacrifice their freedoms in software choices.

\section{Designing for fiscal sustainability}

I trained as an accountant in my first life (and do not readily admit this publically). However, this background has been a tremendous asset in establishing foundations for fiscal sustainability. I'm in the business of raising money so that the foundation does not make profit. That's an order of magnitude harder to do than running a successful commercial business. We decided to build the OERF from a very low cost base of less than US $\$ 200,000$ per annum operating with only two full time staff members for the first 5 years. While this restricted our ability for rapid growth, we saved a ton of money which is now paying dividends because unlike a number of the commercial MOOC providers we do not need to figure out how to pay back millions of dollars worth of venture capital. The other lesson I have applied religiously is to avoid external funding to cover basic operations but to invest donor funding wisely in building strategic capability. In this way we have avoided generating too much dependency on third party donor funding.

\section{The OERu international innovation partnership}

\section{'The OER $u$ envisions a world where all learners have affordable access to higher education'}

The OER universitas (OERu) is a consortium of over thirty post-secondary institutions and organisations (as of March 2016) collaborating on the assembly of university-level courses from OER and providing pathways for learners to achieve formal academic credit towards credible credentials. Coordinated by the OERF, the OERu is an international innovation partnership with member institutions from Africa, Asia, Europe, the Middle-East, Oceania, and North America. ${ }^{5}$ Through the community service mission it is possible for 
organisations to invest time and effort to assemble courses based solely on OER. As accredited institutions, these universities, colleges and polytechnics can provide summative assessment services with pathways for learners to earn formal academic credit and pay reduced fees for assessment and credit when compared to full tuition. By combining the potential of OER with the community service mission, it is possible to create what Taylor (2007) has called a 'parallel universe' of post-secondary learning opportunities to complement and augment formal education provision, especially for those who lack the means to follow traditional learning paths. So for example, sharing course materials funded for mainstream delivery under an open license does not add additional cost for this institution if these are shared with the communities our public funded institutions are established to serve. On the contrary, this enables the organisation to serve a wider community without increasing cost. Figure 1 below illustrates the OERu model which is designed to provide more affordable access to higher education leading to formal academic credit.

Originally conceived as the OER university (OERu) by the participants at the inaugural meeting of interested institutions in February 2012 we always used the lower case 'u.' The lower case 'u' refers to a community of scholars sharing information freely as intended by the original Latin meaning of universitas magistrorum et scholarium from which the word university was derived. In our

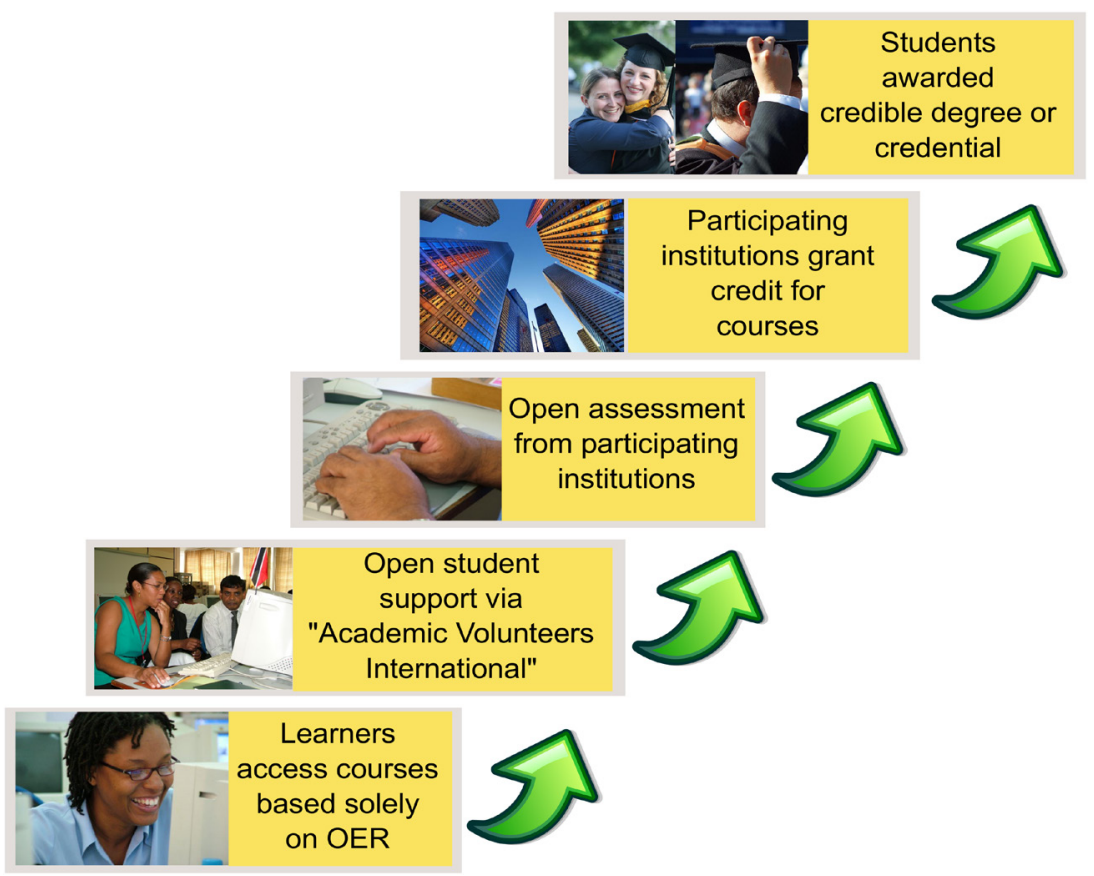

Fig. 1: The OERu Model. 
case, the word 'university' did not refer to the title of formal teaching institution. The name was changed to OER universitas (OERu) when a group of formal universities objected to the use of the term 'university' which is a restricted concept in the Higher Education Acts of a number of countries. ${ }^{6}$ This was a signal that our philanthropic collaboration was coming of age given the interest to assert 'ownership' of the concept 'university.' The OERF Board of Directors approved the adoption of the name 'OER universitas' which in hindsight better reflects the developing nature of the OERu network with increased membership from non-teaching institutions and a growing number of universities, community colleges, and polytechnics joining the network.

\section{Open design and development at the OERu}

Open design refers to the creation and development of potentially meaningful learning experiences through open and transparent collaboration among course developers and peers using open educational resources, open educational practices, and open technologies.

$\mathrm{OERu}$ design and development begins with a simple premise that it is more productive and sustainable to reuse and remix existing resources than to create new ones from scratch. It requires an agile disposition to assemble learning pathways which utilise existing OER and open access resources to support the learner's journey in attaining the learning outcomes. The open design process is highly iterative. Unlike production-line models found at many open distance learning institutions which develop a 'master design plan' which provides detailed direction of the development, the OERu design process accepts that we are more open to iterative change as the development process progresses. It draws on the experiences of open source software development. Eric Raymond compared the differences between open and closed models of software development in his seminal text, The Cathedral and the Bazaar (1999). The cathedral represents the detailed planning and closed development of proprietary software, where users only get to see the functionality and features between major releases and the code developed between releases is restricted to an exclusive group of developers. The bazaar references an approach where all code is developed on the internet in view of the public. Raymond proposed that 'given enough eyeballs, all bugs are shallow' which he terms Linus's Law named in honor of Linus Torvalds who led the development of the kernel of the GNU/Linux open source operating system.

The OERu provides an example of a design and development model which is distinctively open. The entire process from initial course nominations, to preparing design blueprints and developing the course resources is conducted openly on the internet for all to see and participate in. This open approach facilitates more iterative design and development because the design documentation becomes a living document and the open education community can assist with peer review and refinements. So for example, the design blueprint 
for the OERu's Digital Skills for Collaborative Development (DS4OER) course is shared openly with learners wanting to learn how to develop open design frameworks. In this instance, the two lead developers of the course were experienced wiki collaborators so they were able to work with a very basic design expression which evolved as the course development matured, rather than attempting to produce a 'textbook' blueprint to meet corporate design requirements. Learners participating in the course can view the edit history to see how the design evolved over time in conjunction with the wiki discussions associated with each page. The design concepts can easily be copied and are being reused for a wide range of new OERu course developments.

\section{Describing open design}

The concept of open design extends the principles of openness beyond OER materials themselves to include open planning, open design and open development of courses. Open design refers to the dynamic processes for open collaborative design and development of open courses. It draws on the open source software development model to facilitate rapid prototyping and continuous feedback and improvement loops.

In contrast to course development by a sole individual or dedicated production team, the open design approach is characterised by:

1. Participants and teams constituting themselves in self-selected roles using collaborative processes. Anyone is free to volunteer and contribute to the process.

2. A highly iterative design and development process, where people with different skill sets including learning designers, subject matter experts, language editors, and technologists work simultaneously rather than using a production line model with discrete division of labour.

3. A public record of all planning and communications. For example, creating a node page for planning the development in a wiki and using the corresponding discussion pages or posts to public email lists with public access to the archives.

4. Open collaborative authoring technologies which maintain a detailed edit history.

5. Group decision-making informed by rough consensus and running code, a concept coined by David Clark, a computer scientist. In open design, this means that the active collaborators tap into the 'sense of the group' at a given time to prioritise practical implementation knowing that the open model facilitates continuous improvement. In a rough consensus model, a majority agreement (i.e., 51\%) of all listed participants is not required. In open design, it is better to have a working draft than an elaborate master plan agreed by the majority. 


\section{Dimensions of open pedagogy at the OERu}

An open course at the OERu requires that anybody should be able to access the course materials without the need for password access. Individuals must be free to reuse, revise, remix, redistribute, and even sell our open content. The OERF supports the United Nations Declaration of Human Rights including the right to earn a living from our open resources. Our commitment to FOSS and open file formats ensures that educators and learners will be able to retain digital copies of their work.

Unfettered access to our course materials recognises the potential learning value of being able to fail anonymously. This feature could be of value to indigenous learners, first in family university learners, and learners who may perform better without the time constraints associated with completion of traditional courses. We do not know the extent that OERu courses serve these categories of learners because in the absence of mandatory registration we do not track learner progress. However, our server statistics confirm that our open courses attract visits from a large number of individuals who prefer not to register for a course. (At the OERu, course registration is optional for learners who would like to receive instructions via email.)

OER enables designers to implement a 'pedagogy of discovery' whereby learners can be guided to source their own open resources in pursuit of their own interests in achieving the course outcomes. The growing inventory of OERs and open access materials available on the web provides the opportunity to develop courses using a 'free range' learning strategy where learners can customise the content to suit their own needs and interests within the context of a university-level course. ${ }^{7}$

The OERu implemented this 'free range' learning model with a prototype course: USQ's Regional Relations in Asia and the Pacific, the course taken by Michelle Aragon, described at the beginning of this chapter. The Asia Pacific region comprises over forty different countries, and it would not have been possible to prescribe a closed text covering this wide range of countries. Whereas Michelle's work was assessed by the University of Southern Queensland in Australia, she successfully applied her credit towards her credential at Thompson Rivers University in Canada becoming the OERu's first graduate. Reflecting on the power of the model, Michelle notes: 'It was also quite freeing not to be tied to a textbook and able to follow what I wanted to learn about and what I

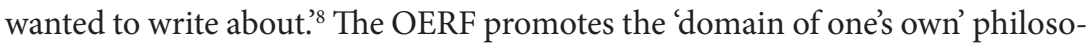
phy where individuals have the freedom to manage and control their own technology and content. OERu course design encourages learners to maintain their own course blogs rather than e-Portfolio systems administered by the OERF or trapping contributions within the learning management system. In this way, learners have control over their own learning artefacts and will retain access to the outputs of their learning long after the course is completed. In another example, the digital skills for collaborative OER development (DS4OER) 
course teaches learners how to administer their own open source blog sites using free cloud-based services. In this way the OERu can empower educators to publish online course websites which may help cash strapped institutions in the developing world who do not have the resources to host their own technology infrastructure.

\section{Lessons learned from implementing the OERu}

In summary, the success of the OERu collaboration to date has been supported by the following guiding principles:

1. Responding to a compelling vision which is well aligned to the core values of the contributing institutions. The vision of providing free learning opportunities for all students worldwide with pathways to achieving affordable degrees, especially for learners who are excluded from the privilege of a tertiary education is a compelling and worthy vision. This is well aligned with the community service missions of the contributing partner institutions.

2. Open sourcing everything. The OERu is distinctively open using open educational resources, open educational practices, open licensing, open source software, and open planning models. Apart from significant cost savings in providing central technology infrastructure, open and transparent planning builds trust for existing and prospective partner institutions. All partners can monitor developments in real time and participate in all aspects of the implementation of the OERu without excluding valuable volunteer contributions from individuals in the open community.

3. Ensuring the decision-making autonomy of partner institutions. A key principle of engagement in the OERu model is the institutional autonomy of partner institutions regarding all decisions relating to the assessment and accreditation of learning. Partner institutions will not jeopardise their institutional stature, brand or credentialing authority yet working collectively the network is able to achieve more than working alone.

4. Generating a viable value proposition for capacity development in open approaches. Without tangible benefits for contributing partners, there is no motivation for institutions to contribute. The OERu enables institutions to participate in an international network while responding to their community service mission. The OERu model enables partner institutions to build capability in open and collaborative design models in online learning while generating opportunities for reducing cost. For example, partner institutions could diversify curriculum offerings for traditionally low enrolment courses which would be too expensive to produce alone, but could easily integrate an OERu course into the curriculum for fullfee students without incurring any capital course development costs. So 
for example, Otago Polytechnic approved a course 'Change with digital technologies in Education,' a Masters level course originally developed by the University of Canterbury, for inclusion in the Graduate Diploma in Tertiary Education. The courses serve two different markets and is a good example of how a course funded by taxpayer dollars can help serve a wider range of institutions and students.

5. Avoiding the temptation to innovate on too many fronts simultaneously beyond the capacity of the economy and society to accept the new developments. While the allure of innovating through technology is appealing, the higher education sector and the economy are traditionally conservative when it comes to the token value of a university degree. The OERu has restricted its primary innovation to using courses based on OER for formal academic credit, and has intentionally left the innovation, for instance, of new forms of credentials like open badges to other players the ecosystem who are arguably better positioned to achieve success.

6. Minimising risk while maximising impact. The OERu network is a low risk opportunity for partner institutions because institutional exposure is limited to the assembly of only two courses from existing OER. However, the collective network returns are significantly greater than the initial investment of individual partners because the open model facilitates reuse and remix. Our open model allows the freedom for partners to contribute more than the minimum. So for example, Otago Polytechnic has 'donated' the Graduate Diploma in Tertiary Education which is a full program exceeding the suggested two course contribution. Recently, five partner institutions have agreed to share the costs of an open source software developer. In short, these partners gain the benefits of a full-time staff member for a portion of the cost because all the code developed through this positions is shared as open source software. On the other hand, 'silent partners' who take longer with their own course contributions still contribute to the greater good because their membership fees assist in maintaining the central infrastructure,

7. Guaranteeing recoupment of future operational costs of contributing partners. The recurrent costs of providing assessment services in the OERu model are recouped on a fee for service basis thus minimising risk for contributing partners and generating opportunities for new revenue streams.

8. Incremental design combined with rigorous strategic planning. It is not possible to develop a detailed master plan for the medium term in a highly volatile and fast moving technology environment in higher education. Moreover, the complexities associated with the dynamics of an international network comprising institutions from six major regions of the world cannot reasonably be anticipated within a rigid master plan. The OERu focuses on incremental projects which are small enough to fail but sufficiently strategic to facilitate organisational learning for the network. In this way the OERu remains agile and responsive to changing needs. 
These principles are not mutually exclusive and interact with each other as a dynamic ecosystem. We believe that the OERu model is sufficiently agile and flexible to enable individual partners to pursue their own priorities without compromising the collective goal of widening access to more affordable education. We continue to learn on this open journey.

I am personally very excited by the OERu network's decision to progress a 'free' first year of study leading to an exit award as 'Minimum viable product.' Our tireless work in building trust through open and transparent planning has paid off as demonstrated by the unanimous decision of the OERu partners to approve the credit accumulation and credit transfer guidelines. It is indeed possible to nurture meaningful cooperation as we return to the core values of the academy which is to share knowledge freely.

\section{Previous publication}

Selected paragraphs in this text are proudly remixed from the author's own openly licensed contributions to:

- The Digital skills for collaborative OER Development open course, Available online at: http://course.oeru.org/ds4oer/

- Open Education Resource Foundation Ltd. Annual Report 2015. In press.

\section{Notes}

${ }^{1} \mathrm{OERu}, 2014$.

2 http://www.apache.org/foundation/how-it-works.html

${ }^{3}$ https://www.mozilla.org/en-US/foundation/

${ }^{4}$ Freedomdefined, 2015.

5 OERu: Undated.

${ }^{6}$ OERF, 2013.

7 Taylor, 2012.

${ }^{8}$ OERu, 2014.

\section{References}

Freedomedefined. (2015). Free cultural works definition. Retrieved from http:// freedomdefined.org/Definition

OER Foundation (2013). The OER university becomes OER universitas. Retrieved from: http://oeru.org/news/the-oer-university-becomes-oer-universitas/

OERu (2014). Meet Michelle Aragon - OERu's first graduate. Retrieved from: http://oeru.org/news/meet-michelle-aragon-oerus-first-graduate/

OERu (Undated). OERu partners. Retrieved from: http://oeru.org/oeru-partners/ 
Raymond, E.S. (1999). The Cathedral and the Bazaar: Musings on Linux and Open Source by an Accidental Revolutionary. Sebastopol, CA: O'Reilly Media. (p. 30) Retrieved from https://books.google.com/books?id=F6qgF tLwpJgC\&pg=PA30\&hl=en\#v=onepage \&q\&f=false

Taylor, J.C. (2007). Open courseware futures: creating a parallel universe. e-Journal of Instructional Science and Technology (e-JIST), 10(1), 4-9.

Taylor, J.C. (2012). The Pedagogy of Discovery: Enabling Free Range Learning. Invited address to the Seminar on Creating and Widening Access to Knowledge Universiti Sains Malaysia, Penang, 26 June. 